\title{
A case study of consensus modelling for tracking oil spills
}

\author{
Brian King $^{1}$, Ben Brushett ${ }^{1,2}$ and Charles Lemckert ${ }^{2}$ \\ ${ }^{1}$ Asia-Pacific ASA, PO Box 1679 Surfers Paradise, QLD, 4817 Australia \\ ${ }^{2}$ School of Engineering, Griffith University, Gold Coast, QLD, 4222 Australia \\ Email: bking@apasa.com.au,bbrushett@apasa.com.au, c.lemckert@griffith.edu.au
}

\begin{abstract}
Metocean forecast datasets are essential for the timely response to marine incidents and pollutant spill mitigation at sea. To effectively model the likely drift pattern and the area of impact for a marine spill, both wind and ocean current forecast datasets are required. There are two ocean current forecast models and two wind forecast models currently used operationally in the Australia and Asia Pacific region. The availability of several different forecast models provides a unique opportunity to compare the outcome of a particular modelling exercise with the outcome of another using a different model and determining whether there is consensus in the results. Two recent modelling exercises, the oil spill resulting from the damaged Pacific Adventurer (in Queensland) and the oil spill from the Montara well blowout (in Western Australia) are presented as case studies to examine consensus modelling.
\end{abstract}

\section{Introduction}

The two ocean current forecast models currently being used operationally in the Australian and greater Asia Pacific region are the US Navy Coastal Ocean Model (NCOM) and the Australian BLUElink model. Both of these models were developed for large to mesoscale ocean circulation, and as such neither model includes the effects of tidal currents. This lack of tidal current forcing limits the effectiveness of the models in shallow near coastal waters, where tidal currents are important and can be the dominant driving force in water circulation. Asia-Pacific ASA has developed an aggregation tool which combines the effects of both coastal tidal currents and large scale oceanic currents. The tool functions by spatially and temporally interpolating the large scale currents on to the higher resolution, tidal currents using vector addition, thus producing a very effective current forecast dataset able to be used in both open ocean and coastal waters alike.

The two wind forecast models used in this study were the US Global Forecast System (GFS) and the US Navy Operational Global Atmospheric Prediction System (NOGAPS). Wind forcing is a very important factor when modelling the drift trajectories of marine pollutant spills. This is due to the oil slick moving with the water body as a result of the currents, as well as the oil slipping across the water surface due to the effects of the wind.

The availability of several different forecast models provides an additional opportunity to compare the outcomes of a particular modelling exercise. This is done by varying the input data from one forecast model to another and comparing the results. If the outcomes are similar, then there is consensus between the datasets, and the modeller can be confident that the forecast is more reliable. If there is a discrepancy between the forecasts, then there is no consensus, which suggests that the forecast may not be as reliable. In such a situation it is necessary for the modeller to further interogate the input data to ascertain which may be the most reliable forecast. 
Two recent emergency responses involving pollutant forecast modelling were investigated using input data from the Environmental Data Server (EDS) in OILMAP v6, to forecast the fates and trajectory of the spilled pollutants. The first was the Pacific Adventurer oil spill which occurred off Moreton Island, Queensland; and the second was the Montara well blow out which occurred in the Timor Sea, Western Australia.

\section{Metocean forecast models and ASA modelling software}

\subsection{BLUElink}

There are several components to the BLUElink system, including operational forecasts, reanalysis and data assimilation. The operational forecasts from BLUElink were derived from the Ocean Model Analysis and Prediction System (OMAPS-fc). This system uses the Ocean Forecasting Australia Model (OFAM) [1]. The 3D model has a horizontal resolution of $1 / 10^{\circ}$ in the Australian region $\left(90^{\circ} \mathrm{E}\right.$ $\left.-180^{\circ} \mathrm{E}, 75^{\circ} \mathrm{S}-16^{\circ} \mathrm{N}\right)$. The vertical resolution is a 47 layer z-coordinate system, with the topmost layer being $10 \mathrm{~m}$ thick. Forecast length is 144 hours, at intervals of 24 hours [2]. Data assimilation is controlled by the BLUElink Ocean Data Assimilation System (BODAS) which is an ensemble optimal interpolation (EnOI) scheme that assimilates Sea Surface Temperature (SST), Sea Surface Height (SSH) and temperature and salinity profiles. Atmospheric fluxes are provided by the Global Atmospheric Prediction System (GASP) [3].

\subsection{NCOM}

The Navy Coastal Ocean Model is based on the Princeton Ocean Model (POM) and has global coverage with a horizontal resolution of $1 / 8^{\circ}$. Vertical resolution is a $\sigma$-z coordinate system with $19 \sigma-$ coordinate layers in the upper $137 \mathrm{~m}$ (topmost surface layer thickness of $1 \mathrm{~m}$ ) and $21 \mathrm{z}$-coordinate layers from $137 \mathrm{~m}$ to $5500 \mathrm{~m}$. Forecast length is 72 hours, at time intervals of 6 hours. Data assimilation is controlled by the Modular Ocean Data Assimilation System (MODAS) which assimilates temperature, salinity and SSH. Atmospheric forcing is provided by the Navy Operational Global Atmospheric Prediction System (NOGAPS) atmospheric fluxes [4].

\subsection{GFS}

The Global Forecasting System (GFS) is a global spectral numerical model operationally run by the US National Oceanic and Atmospheric Administration (NOAA). The T254 version (used in this study) provides global coverage with a horizontal resolution of $1 / 2^{\circ}$ with 64 unequally spaced vertical layers. The forecast length is 180 hours, and the temporal resolution is 6 hours [5].

\subsection{NOGAPS}

The Navy Operational Global Atmospheric Prediction System (NOGAPS) is the principal source of atmospheric forcing for the US Navy ocean models (e.g. NCOM) and short term numerical weather prediction (NWP). NOGAPS has global coverage, with horizontal resolution $\sim 1 / 2^{\circ}$. The forecast length of the NOGAPS product is 144 hours with temporal resolution of twelve hours (at 00 and 12 UTC) and updates at 06 and 18UTC to enable background forecasts. Outputs from the model include momentum flux, both latent and sensible heat fluxes, precipitation, solar and long wave radiation and surface pressure, as well as 10 metre $\mathrm{U}$ and $\mathrm{V}$ wind velocities [6,7].

\subsection{OILMAP v6}

OILMAP is a modelling system designed for predicting the physical and chemical fates and effects of hydrocarbon spills in the marine environment. It contains a trajectory model which uses a large number of Lagrangian particles to simulate the trajectory, as well as a number of algorithms which account for hydrocarbon spreading, evaporation, emulsification, entrainment, and shoreline interactions. Time and space varying environmental data (speed and direction of winds and water currents) provide forcing to simulate the drift of hydrocarbon slicks. To account for variability in the 
inputs (such as wind gusts) uncertainty particles are included in the model runs. These uncertainty particles are subjected to winds and water currents that have been varied by up to $\pm 30 \%$ of their strength and \pm 30 degrees in direction.

Dispersion of the hydrocarbon slick is controlled by the horizontal dispersion parameter. A typical value for this during strong winds and rough seas is $35 \mathrm{~m}^{2} \mathrm{~s}^{-1}$, as the strong winds and large waves tend to rapidly break the slick up and disperse it. During calmer conditions with light winds and calm seas typical values can be as low as $0.5 \mathrm{~m}^{2} \mathrm{~s}^{-1}$. Other parameters include wind factor and wind angle, these values control the amount the slick is influenced by the effects of the wind by defining the relative movement of the slick across the water surface in relation to the strength and direction of the wind.

Predictions of the OILMAP model have been validated worldwide [8] and in Australia [9] by field observations and by hind-casting past hydrocarbon spills. For consensus forecasting purposes in this case study, all parameters were kept consistent between each model run, only the input winds and currents were changed; this ensured only the input data would have an effect on the modelling forecasts.

\subsection{HYDROMAP}

The two-dimensional tidal currents (which were aggregated with ocean currents from NCOM and BLUElink) were generated using an advanced ocean/coastal model, HYDROMAP. The HYDROMAP model has been tested and verified through field measurements throughout the world over past twenty-five years [10]. HYDROMAP employs a sophisticated multi resolution gridding system, which enables six levels of spatial resolution. The sub-gridding allows for higher resolution of currents within areas of greater bathymetric and coastline complexity. The input data for this hydrodynamic model was Geoscience Australia $250 \mathrm{~m}$ resolution gridded bathymetry, and open boundaries loaded with the eight dominant tidal constituents from the TPXO7.1 TOPEX-Poseidon global inverse tidal model [11].

\subsection{COASTMAP Environmental Data Server (EDS)}

The EDS automatically downloads, stores, catalogues and disseminates metocean forecast and hindcast data, such as winds and oceanic currents for use within OILMAP. The format of the data collected is often disparate, however the EDS is able to serve the data in a commonly accessible form. Currently available in the Australasian region are NCOM and BLUElink forecast ocean currents, HYDROMAP tidal currents and GFS and NOGAPS forecast winds. Also included in the EDS is an aggregation tool which takes the oceanic currents and aggregates them with tidal currents. This aggregation process spatially interpolates the ocean currents from their coarse resolution grids onto a finer variable resolution grid, at the resolution of the tidal current model. The ocean forecast currents and winds are also temporally interpolated from 24 or 6 hourly intervals to one hourly intervals.

\section{Consensus modelling case studies}

\subsection{Case Study 1 - Pacific Adventurer spill}

In the early hours of the morning on the 11th of March 2009 the Pacific Adventurer encountered severe weather conditions off the Coast of Moreton Island. Due to this severe weather, 31 shipping containers were lost overboard. In the process several of the containers ruptured the ships fuel tanks which resulted in the loss of 270 tonnes of heavy fuel oil to the marine environment at the water surface [12]. Asia-Pacific ASA provided modelling support to determine the likely fates and possible shoreline strikes of this heavy fuel oil.

Figure 1 shows the various model runs completed using OILMAP, and environmental forecast data from the COASTMAP EDS. NCOM and BLUElink forecast currents aggregated with tidal currents provided the current forcing, whilst GFS and NOGAPS wind forecast models provided wind forcing. As shown, there is a general consensus between the model forecasts. All four model forecasts show that the shorelines on the northern end of Moreton Island and the beaches near Kawana will be 
impacted, with the possibility of shoreline impacts to the beaches both north and south of the Kawana Beach region. The best correlation between the model predicted shoreline impacts and observed shoreline impacts was attained by using NCOM predicted currents aggregated with tidal currents, and the GFS forecast winds.

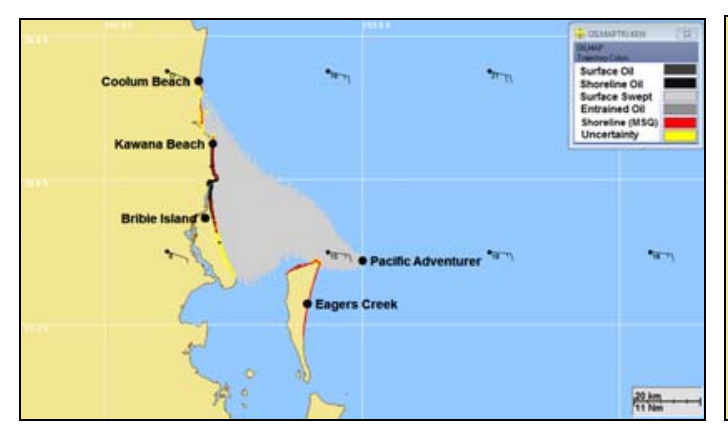

BLUElink + Tides \& GFS

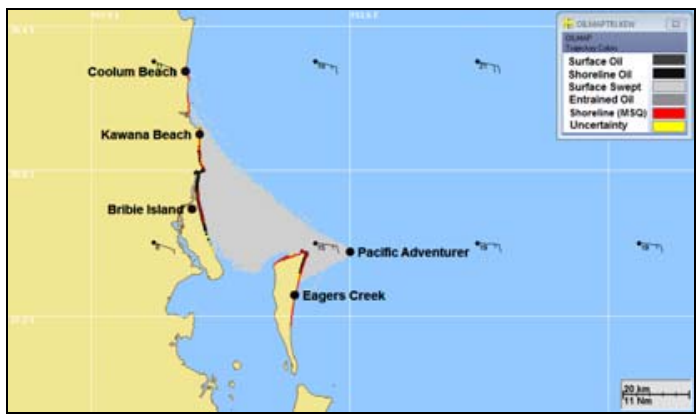

$\mathrm{NCOM}+$ Tides \& GFS

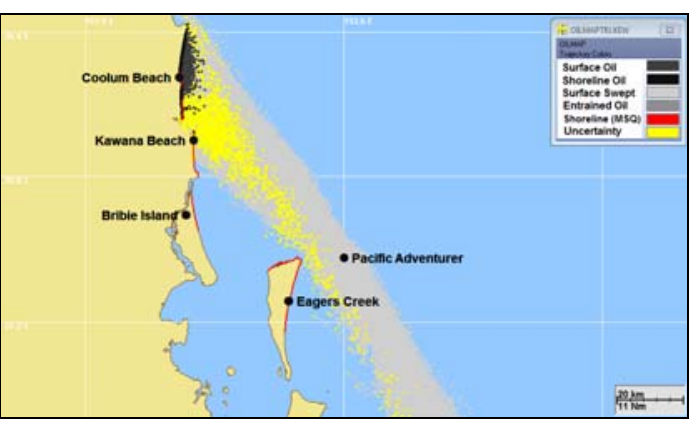

BLUElink + Tides \& NOGAPS

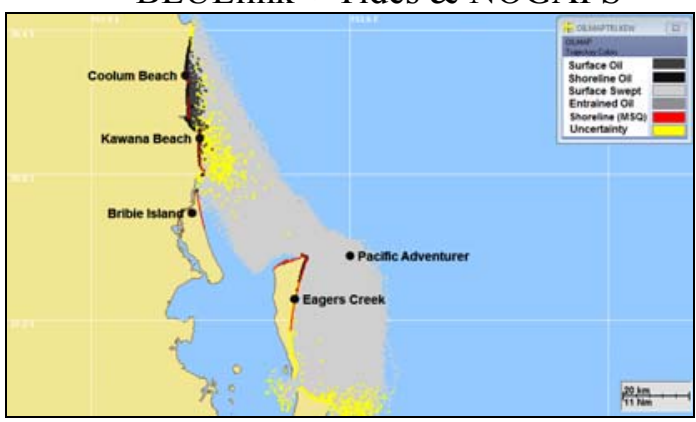

NCOM + Tides \& NOGAPS

Figure 1. The four different model runs completed when forecasting the Pacific Adventurer spill. The dark grey dots represent the surface oil, the light grey dots represent the water surface swept by the oil over the 3 days modelled, the yellow represents the "uncertainty particles" used by the model, the black represents the oil stranded on the shorelines, as predicted by the model, and the red indicates the full extent of the shoreline oil stranding as reported by Maritime Safety Queensland (MSQ). Note that the model shoreline stranded particles can be difficult to see under the red observed shoreline stranding of oil, however the swept area gives an indication of the shorelines impacted.

\subsection{Case Study 2-Montara Well head blowout}

At approximately 4 am WST on the 21st of August 2009, a leak formed at the Montara well head, located approximately $680 \mathrm{~km}$ west of Darwin off the Kimberley coast in Western Australia. It was estimated that around 400 barrels per day of crude oil was being discharged into the sea from the well head platform above the water surface. The leak continued for 74 days until the well was successfully "killed" on the 3rd November 2009. This equates to a total of almost 30,000 barrels of crude oil being released into the marine environment [13]. Asia-Pacific ASA was involved in the provision of modelling support throughout this incident. The forecasting of the spill proved to be very difficult, especially in the initial stages of the incident. At the beginning there was no consensus between the forecast models, with a different direction of travel predicted for the NCOM plus tidal currents and the BLUElink plus tidal current forecast data (see figure 2). As shown, the NCOM tidal aggregation predictions show the oil plume moving towards the West, whereas the BLUElink tidal aggregation shows the oil plume moving in a Northerly direction. Two surface drifters were deployed which showed the currents moving in an easterly direction (different to both NCOM and BLUElink). They also showed that the currents were tidally influenced (as indicated by the tidal oscillations in the buoy trajectories). This shows that for predicting drift patterns in this region, the addition of the tidal component to the surface currents is important. As the incident continued, the forecast datasets proved to better resolve the surface currents in the region when compared to drifter tracks, location of 
predicted and observed surface oil, and when directly comparing the NCOM and BLUElink currents with hindcast currents. Of the 13 weeks that the oil was tracked, approximately 10 weeks returned good current forecast data.

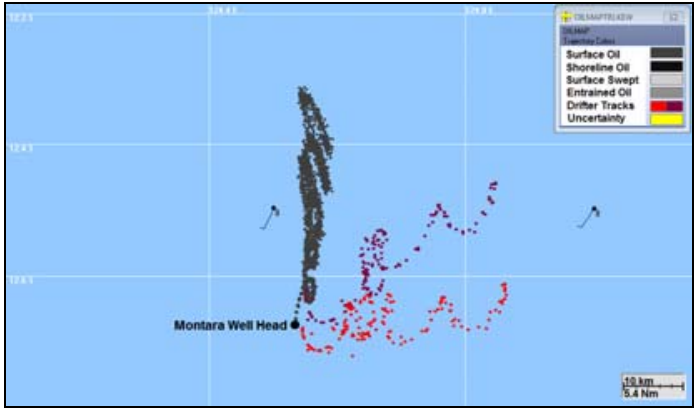

BLUElink + Tides \& GFS

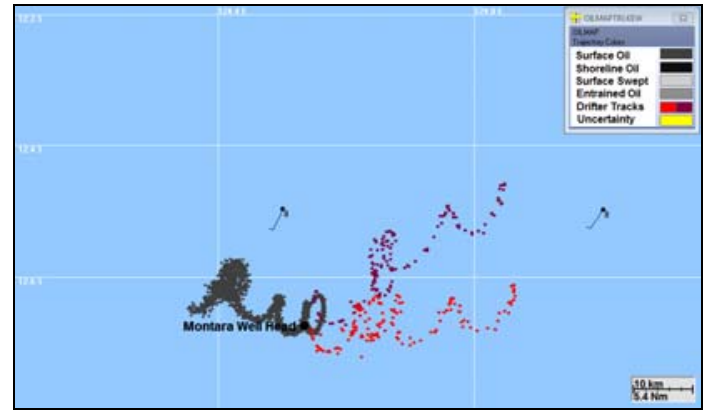

$\mathrm{NCOM}+$ Tides \& GFS

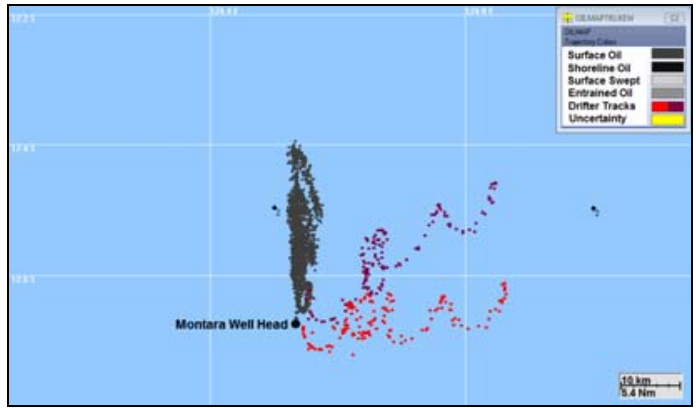

BLUElink + Tides \& NOGAPS

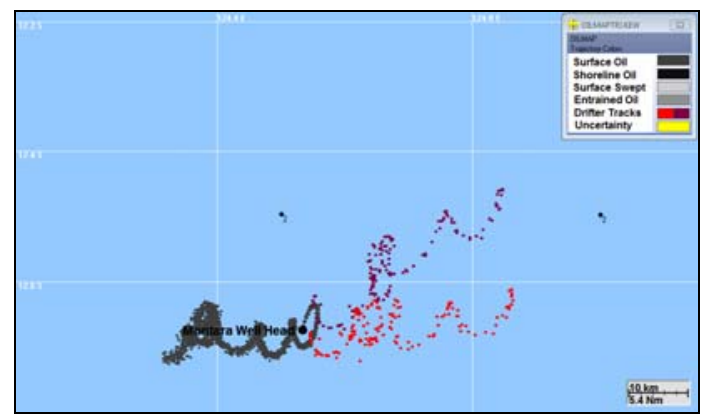

NCOM + Tides \& NOGAPS

Figure 2. The four different model runs completed when forecasting the Montara well blowout. The light grey area represents surface area swept by the oil over the first three days of the modelled spill, the dark grey represents surface oil particles and the red and maroon points show the tracks of the surface drifters which were deployed to ground truth the currents.

\section{Discussion}

Different forcing was dominant for each of the incidents studied, due to the nature of the environmental conditions at the time of the spills. Wind forcing was dominant over surface currents for the Pacific Adventurer spill due to the incident occurring at the end of a large storm, which produced model winds at an average of 20 knots, up to a maximum of 28 knots (over the 3 days modelled), whilst surface currents had less of an effect as they averaged around 1 knot with maximum of 2.5 knots. This is in contrast to the Montara incident which occurred in comparatively calm weather with model winds that only averaged around 5 knots, up to a maximum of 10 knots and where tidally governed surface currents averaged around 0.7 knots with a maximum of up to 1.4 knots.

When consensus between forecast models is achieved, the outcome is potentially more reliable, however as shown in the two case studies above, consensus is not always reached. One reason for this is the positioning of mesoscale eddies, which have spatial extents in the order of tens of kilometers. As the two aforementioned global current forecast models (NCOM and BLUElink) have spatial resolutions of approximately $10 \mathrm{~km}$, their ability to effectively model mesoscale eddies can be limited. To adequately resolve mesoscale eddies, a much finer resolution is required. Problems arise with ocean forecast models when eddies are misplaced. This is particularly evident as the eastern side of a clockwise rotating eddy will spin an object to the south, whereas if the eddy is moved such that the object is now placed on the western side, the particle will be pushed in the complete opposite direction, towards the north.

One possible reason that NCOM performed slightly better than BLUElink in the Pacific Adventurer incident is that the incident occurred quite close to shore in shallow waters. NCOM has a grid which can resolve to a minimum of $5 \mathrm{~m}$ depth, where the BLUElink model is currently only able to resolve to a minimum of $20 \mathrm{~m}$ water depth, thus making it less effective in shallow waters. 


\section{Conclusions}

As shown in the Pacific Adventurer case study, all four metocean forecast datasets can be used to effectively model the movement of oil in the marine environment, however the Montara case study shows that this is not always the case, and a sound understanding of the inputs and their strengths and limitations is required to effectively forecast the drift of oil. If consensus is reached between the models, then the forecaster has a higher degree of confidence of a more reliable outcome; if consensus is not reached, then there is a lower degree of confidence. It was also evident that in both cases the tidal circulation component of the surface currents was important. This was due to both incidents occurring in relatively shallow coastal environments (less than $200 \mathrm{~m}$ deep). Without the inclusion of tides, the predictions may not have been as effective.

\section{Acknowledgements}

This research was supported under the Australian Research Council's Linkage Projects funding scheme LP0991159.

\section{References}

[1] Andreu-Burello I, Brassington G, Oke P and Beggs H 2010 Including a new data stream in the BLUElink Ocean Data Assimilation System Aust. Met. and Oceanogr. J. 59 77-86

[2] Australian Bureau of Meteorology. BLUElink> Ocean Model Analysis and Prediction System version 1.0 (OceanMAPSv1.0) Technical Specification [document on the Internet]. Canberra [updated July 2007; cited 2010 March 5]. Available from: http://www.bom.gov.au/oceanography/forecasts/technical_specification.pdf

[3] Brassington G B, Pugh T, Oke P R, Freeman J, Andreau-Burrel I, Huang X and Warren G 2009 Operational Ocean Data Assimilation for the BLUElink Ocean Forecasting System, Fifth WMO Symposium on the Assimilation of Observations for Meteorology, Oceanography and Hydrology, Melbourne, 5-9 October 2009

[4] Barron C N, Birol Kara A, Rhodes R C, Rowley C and Smedstad L F 2007 Validation Test Report for the $1 / 8^{\circ}$ Global Navy Coastal Ocean Model Nowcast/Forecast System. Naval Research Laboratory, Stennis Space Centre

[5] Environmental Modelling Centre. The GFS Atmospheric Model [document on the Internet] [Updated August 28 2003; cited 2010 March 5]. Available from: http://www.emc.ncep.noaa.gov/gmb/moorthi/gam.html

[6] Rosmond T E, Tiexiera J, Peng M and Hogan T 2002 Navy Operational Global Atmospheric Prediction System (NOGAPS): Forcing for Ocean Models Oceanogr. Mag. 15 99-108

[7] Rosmond T E 1992 The design and testing of the Navy Operational Global Atmospheric Prediction System Weather. Forecast. 7 262-272.

[8] Spaulding M, Kolluru V, Anderson E and Howlett E 1994 Application of three-dimensional oil spill model WOSM/OILMAP to hindcast the Braer Spill Spill. Sci. Technol. B. 123

[9] King B, McAllister F and Hubbert G 1999 Data requirements for calibration and validation of the spill model OILMAP in Marine Meteorology and Related Oceanographic Activities. WMO Report No. 44. MARPOLSER 98 Proceedings 1 WMO/TD - No. 959 35-52

[10] Zigic S, Zapata M, Isaji T, King B and Lemckert C 2003 Modelling of Moreton Bay using an ocean/coastal circulation model Coast and Ports Australasian Conference 9 -12 September Auckland, New Zealand

[11] Egbert G D and Erofeeva S Y 2002 Efficient inverse modeling of barotropic ocean tides $J$. Atmos. Ocean. Technol. 19 183-204

[12] Asia-Pacific ASA 2009 Independent Assessment of the Shoreline Cleanup Operations For the Pacific Adventurer Oil Spill Report to Maritime Saftety Queensland by APASA. Gold Coast

[13] PTTEP Australasia. Frequently Asked Questions Montara Incident [document on the Internet]. West Perth. [cited 2010 January 2] Available from: http://www.au.pttep.com/faq.asp\#Q3 